\title{
Anterolateral Approach for Unstable Lumbar Burst Fracture with Anterior Compression
}

\author{
Wael A. Hammad, Mohamed A. Barania, Islam M. Alaghory, Ahmed M. El Sherif \\ Department of Neurosurgery, Al-Azhar University Hospitals, Cairo, Egypt \\ Email: waelhammad78@yahoo.com
}

How to cite this paper: Hammad, W.A., Barania, M.A., Alaghory, I.M. and El Sherif, A.M. (2018) Anterolateral Approach for Unstable Lumbar Burst Fracture with Anterior Compression. Open Journal of Modern Neurosurgery, 8, 201-214.

https://doi.org/10.4236/ojmn.2018.82017

Received: January 8, 2018

Accepted: April 9, 2018

Published: April 12, 2018

Copyright () 2018 by authors and Scientific Research Publishing Inc. This work is licensed under the Creative Commons Attribution International License (CC BY 4.0).

http://creativecommons.org/licenses/by/4.0/

\section{(c) (i) Open Access}

\begin{abstract}
Background: Lumbar burst fractures are common spinal injuries that cause severe instability with kyphotic deformities and neurological complications requiring surgical decompression and reconstruction with spinal instrumentation for unstable burst fracture, but there is controversy about the optimal surgical approach anterior, posterior or combined approach. Objectives: To assess the efficacy \& safety of anterolateral approach in decompression and reconstruction with spinal instrumentation for lumbar burst fractures. Subjects \& Methods: A retrospective study including 16 patients, 10 males and 6 females with lumbar burst fractures and anterior compression treated operatively by anterolateral approach for corpectomy and single level fusion by using expandable cage or mesh cage loaded with bone graft and plat with screws. The clinical and radiological follow up after discharge from the hospital ranged from 12 to 24 months. Results: All patients improved regarding the Frankel score more than one grade after surgery, except 2 cases of grade A didn't improve. Mean preoperative visual analogue scale was 7.4 improving to 0.9 postoperatively. The mean Local kyphosis improved from $8.8^{\circ}$ before surgery to $-1^{\circ}$ after surgery. Conclusions: Anterolateral approach is feasible, effective, and safe approach for unstable lumbar burst fractures. Angular deformity is successfully corrected when the anterior approach is used.
\end{abstract}

\section{Keywords}

Burst Fracture

\section{Introduction}

Lumbar burst fractures are common spinal injuries that made severe instability and intra canal bony fragments [1]. The mechanism of retropulsion of bone fragments from the fractured endplates into the spinal canal is accepted by many to be the high energy transferred to the vertebral body during major trauma 
leading to increased risks of neurological complications and kyphotic deformities [2]. Patients with neurological deficits require surgical decompression and reconstruction with spinal instrumentation for unstable burst fracture, but there is controversy about the optimal surgical approach in management of lumbar burst fractures, anterior, posterior or combined approach [1] [3] [4].

Highly unstable spine fracture with load sharing scores (LSS) $\geq 7$ should be treated by anterior column reconstruction [5]. For highly unstable thoracolumbar burst fractures, anterior decompression and reconstruction have been developed with a variety of anterior implant systems, which have achieved satisfactory results [6] [7].

The posterior route through laminectomy or the transpedicular-transfacetal route has been described also to access to the canal by laminectomy with or without removal of the facet joints and pedicle, generally on one side, and decompression is achieved by disimpaction. Posterior stabilization generally requires that the instrumentation be placed two levels above and below the site of injury [8] [9].

Some cases may need combined approach anterior and posterior, but this may increase the risk of operative morbidity due to vascular and pulmonary complications [10] [11], particularly in compromised elderly patients [12] [13].

The anterolateral retroperitoneal approach allows the surgeon to perform corpectomy and fusion, reconstructing the anterior and middle columns of the spine. Following corpectomy, the vertebral column is reconstructed by inserting a graft or prosthesis, correcting angulation and loss in vertebral body height. When placing anterior instrumentation for immobilization and fusion, the hardware generally incorporates one vertebral body above and one below to the fracture level [14] [15].

\section{Subjects and Methods}

16 patients were recruited in this study, 10 males and 6 females, with age ranged from 25 to 50 years with unstable lumbar burst fractures with anterior compression on the spinal canal treated operatively by anterolateral approach for corpectomy and single level fusion by using expandable cage or mesh cage loaded with allograft and plate with screws between April 2013 and June 2016. The period between admission and surgery ranged from 5 to 15 days. Surgical indication for this study was traumatic lumbar burst fracture with load sharing scores (LSS) $\geq 7$, thoracolumbar injury classification and severity score (TLICS) $\geq 6$ and with anterior canal compromise [6]. On admission all patients underwent plain (AP and lateral) supine radiographs in CT and MR imaging. Kyphotic angle was measured from the superior endplate of the vertebral body above the fractured level to the inferior endplate of the vertebral body below the affected vertebra was measured on lateral radiograms in the neutral position, before and immediately after surgery, and the final follow-up examination. Neurological status was assessed pre and post operative at time of discharge using the Frankel motor score system. The extent of instability was graded using LSS, as described 
by McCormack et al. [5]. The duration of follow-up was ranged from 12 to 24 months. At each visit, $\mathrm{x}$-ray spine AP and Lateral with neurological assessment by Frankel motor score system were done for all patients.

\section{Inclusion and Exclusion Criteria for Patients Selection}

\subsection{Inclusion Criteria}

1) Trumatic lumbar burst fracture with anterior canal compromise

2) Load sharing scores (LSS) $\geq 7$

3) Thoracolumbar injury classification and severity score (TLICS) $\geq 6$

\subsection{Exclusion Criteria}

1) Lumbar burst fracture without anterior canal compromise

2) Neurologically intact patients

3) LSS $<7$

4) TLICS $<6$

\section{Surgical Technique}

The patient was positioned in lateral decubitus with right side down. The approach was done from the left side to avoid the liver and IVC, dealing and mobilization with aorta was easy and less susceptible to injury than IVC. Oblique skin incision on the level of exposure was required. The incision was centered on the approached level based on fluoroscopy image. The skin and subcutaneous tissue were opened, resection of 11th or 12th ribs was done after subperiosteal separation to reach L1-L2 extrapleurally and we released the diaphragm in L1 fracture cases to put screws in D12 lateral fibers of the abdominal muscles (external oblique, internal oblique, and abdominal transverse) could be opened carefully. Our guide was the extrapertoneal fat, retroperitoneal area was reached without entering the pleural cavity, peritoneum with the ureter and aorta are retracted anteriorly and medially protected with moist gauze. The psoas muscle was stripped from its attachments to the L1 and L2 vertebrae using the vertebral column as a guide, we used self retaining ring retractor, the segmental vessels were ligated, and the periosteum wass exposed. Identification of the level by C-arm partial corpectomy (Figure 1(a)) started trying to preserve its anterior portion to avoid injury to soft structures using a high speed drill, with exposure of the anterior dural sac. Afterwards, short segment instrumentation and bone fusion was done by putting the screws one vertebral body above and one below to the fractured level then expandable cage (Figure 1(b)) or mesh (Figure 1(c)) loaded by bone graft applied with plate above it (Figure 1(d), Figure 1(e)) and tightening of set screws after that closure with drain insertion.

\subsection{Follow-Up Data}

Post operative AP and lateral x-ray films were done then, Patients were advised 


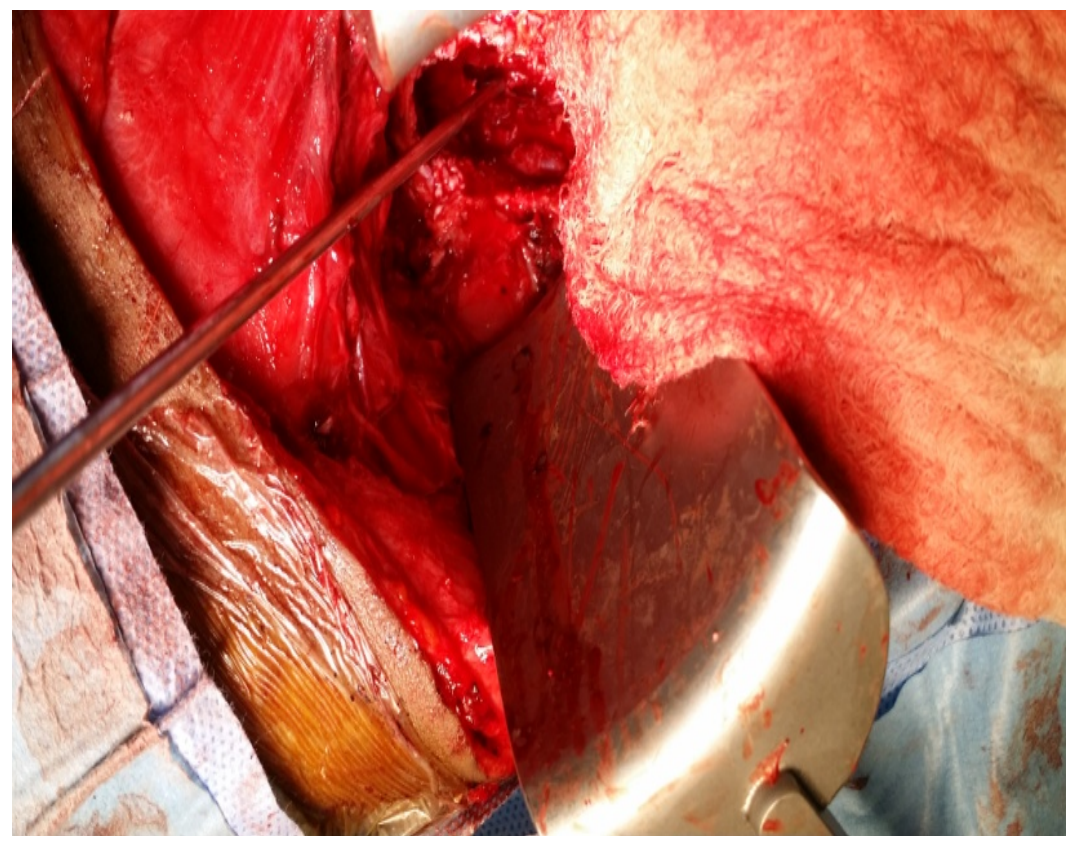

(a)

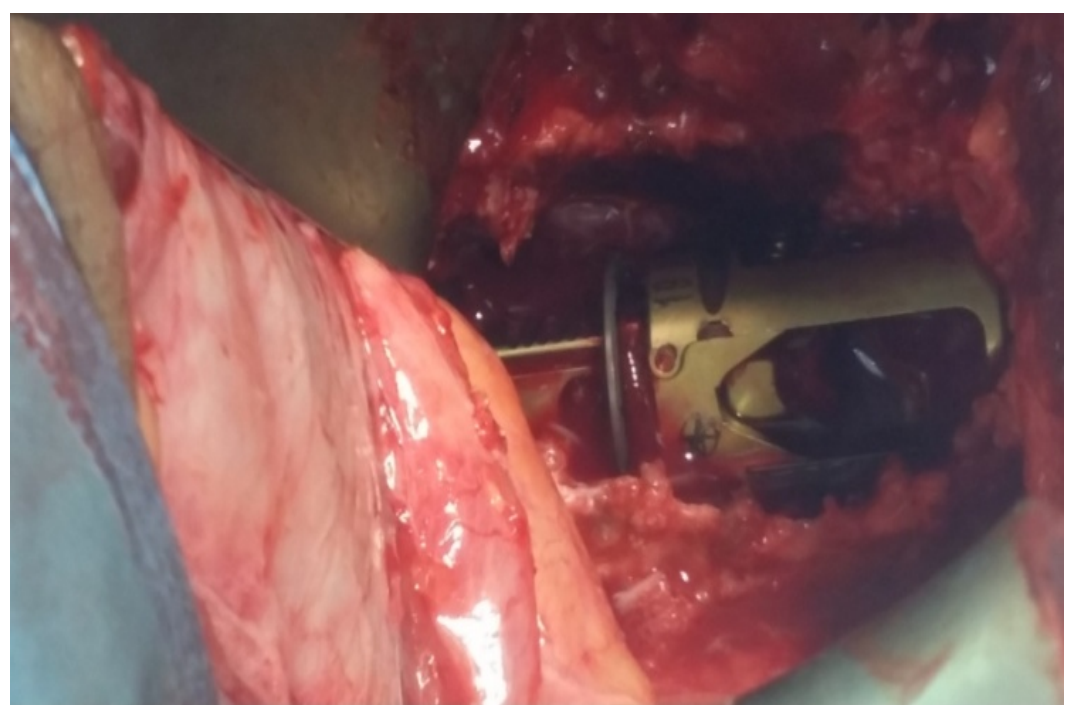

(b)

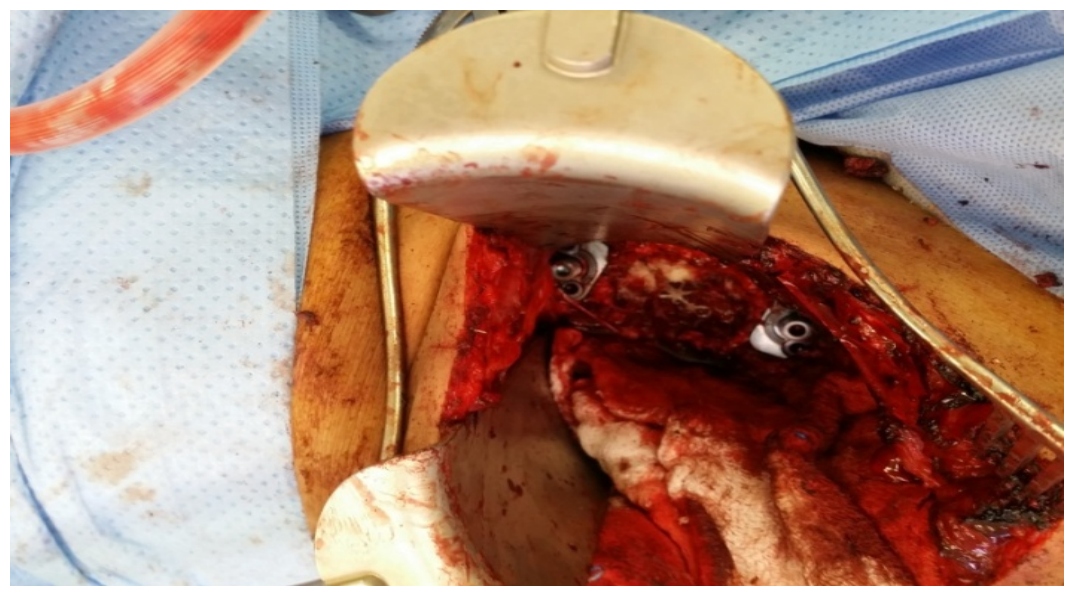

(c) 


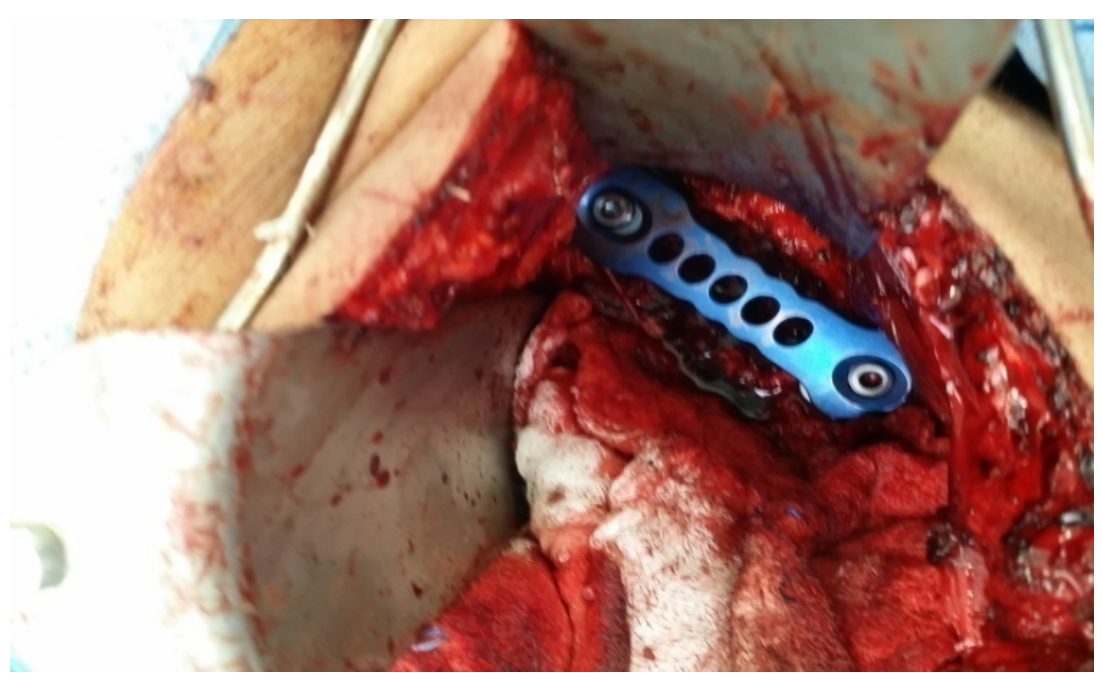

(d)

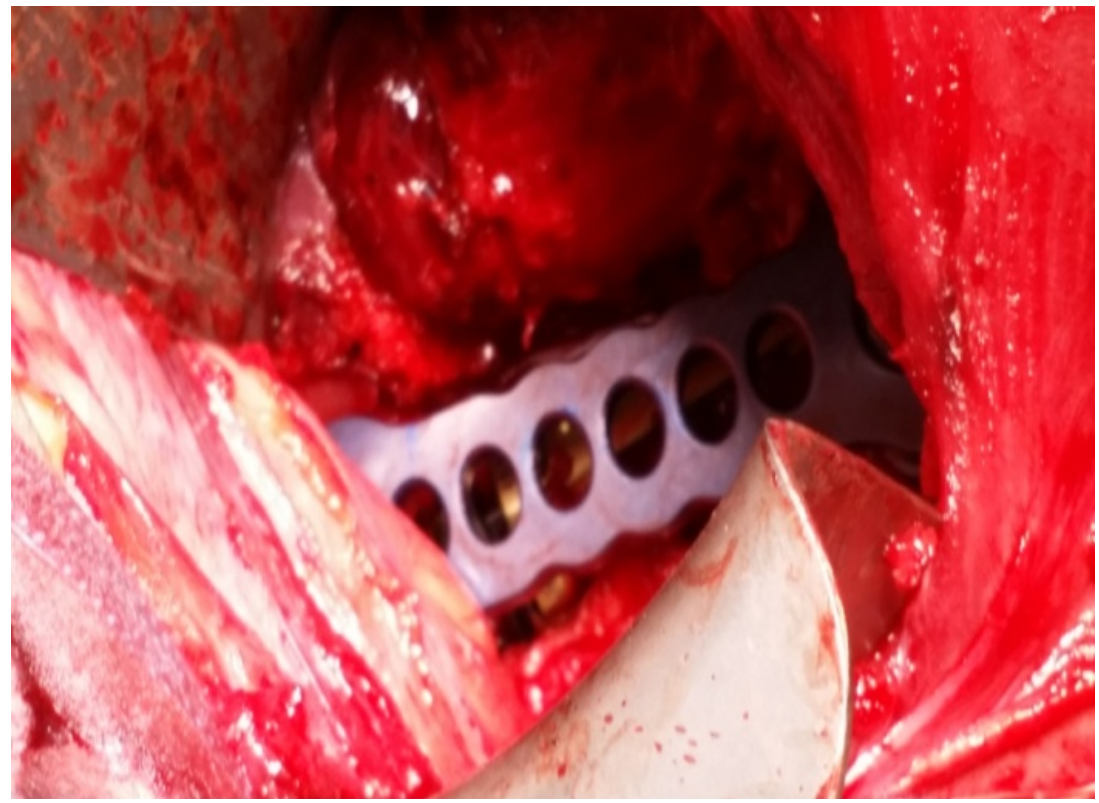

(e)

Figure 1. (a) Intra operative image showing corpectomy of L2 was done with preparation before instrumentation; (b) Expandable cage loaded with bone graft; (c) Mesh loaded with bone graft screws applied at L4 and L3 body; (d) Anterior plate with set screw applied above the mesh; (e) Anterior plate applied above the expandable cage.

to start mobilization while wearing lumbar support, drain usually removed 48 hours after surgery, Lumbar support were generally worn for one month postoperatively. Follow up evaluation including neurological assessment by Frankel motor score system standing or upright AP and lateral radiography were scheduled at $1.5,3,6$, and 12 months and annually thereafter. The duration of follow-up was ranged from 12 to 24 months.

\subsection{Statistical Analysis}

Differences in clinical findings (Fankel score, kyphotic angle and VAS) among 
all patients recruited in the study were compared $\mathrm{b}$ pre and postoperatively.

\section{Results}

The demographic data of pre and postoperative characteristics for each of the 16 patients recruited in the study were listed in Table 1 . The patients 10 males, and 6 females (Figure 2) with mean age 34.2 years ranged from 25 to 50 years, the commonest level is L1 in all of our patients (Figure 3) which had TLICS $\geq 6$ with mean 7.4 ranged from 6 to 8. Regarding Frankel score All of the patients improved at least one level after surgery except 2 cases with preoperative score A didn't improve. Mean preoperative pain score VAS was 7.4 (range from 6 to 9) and postoperative mean of VAS is 0.9 with (range from 0 to 2 ) until final follow up. A significant difference was present between pre and postoperative scores (Figure 4). Regarding the kyphotic angle improved from the mean angle $8.8^{\circ}$ (range from $-6^{\circ}$ to $20^{\circ}$ ) before surgery to the mean angle $-1^{\circ}$ (range from $-10^{\circ}$ to $4^{\circ}$ ) after surgery and final follow-up. A significant difference was seen between kyphotic angle preoperatively and at final follow-up $(\mathrm{p}=0.0001)$ in all cases. The total kyphotic correction was $9.9^{\circ}$ on average (range from -8 to 16 ) one patient (Case 8) needed supplementary posterior Instrumentation and fusion 6 months after the anterior approach due to worsening of the kyphotic angle after failure of bone fusion.

Table 1. Summary of pre and post operative data for all patients.

\begin{tabular}{|c|c|c|c|c|c|c|c|c|c|c|c|}
\hline \multirow{2}{*}{ patients } & \multirow{2}{*}{$\begin{array}{l}\text { Age } \\
\text { sex }\end{array}$} & \multirow{2}{*}{ level } & \multicolumn{2}{|c|}{ Frankel score } & \multirow{2}{*}{$\begin{array}{l}\text { Load } \\
\text { sharing } \\
\text { scale }\end{array}$} & \multirow{2}{*}{$\begin{array}{c}\text { TLICS } \\
\text { score }\end{array}$} & \multicolumn{2}{|c|}{ Kyphotic angle } & \multicolumn{2}{|c|}{ VAS } & \multirow{2}{*}{ Complication } \\
\hline & & & Pre op & Post opl & & & pre op & Post op & Pre op & post op & \\
\hline 1 & $30 \mathrm{M}$ & L 1 & A & A & 8 & 7 & 20 & 4 & 8 & 1 & Pleural injury \\
\hline 2 & $25 \mathrm{M}$ & L 2 & $\mathrm{C}$ & $\mathrm{E}$ & 7 & 8 & 5 & 1 & 6 & 0 & - \\
\hline 3 & $28 \mathrm{~F}$ & L 3 & $\mathrm{D}$ & $\mathrm{E}$ & 7 & 7 & 5 & -10 & 8 & 2 & - \\
\hline 4 & $35 \mathrm{M}$ & L 1 & $\mathrm{C}$ & $\mathrm{D}$ & 8 & 8 & 15 & 2 & 9 & 1 & - \\
\hline 5 & $40 \mathrm{~F}$ & L 2 & B & $\mathrm{D}$ & 7 & 7 & 13 & 3 & 9 & 1 & Peritoneal injury \\
\hline 6 & $45 \mathrm{M}$ & L 3 & $\mathrm{C}$ & $\mathrm{D}$ & 7 & 8 & 5 & -10 & 8 & 1 & - \\
\hline 7 & $26 \mathrm{~F}$ & L 2 & $\mathrm{C}$ & $\mathrm{E}$ & 7 & 7 & 10 & 0 & 8 & 1 & - \\
\hline 8 & $33 \mathrm{M}$ & L 1 & A & A & 7 & 7 & 0 & 8 & 7 & 2 & Worsening of kyphotic angle \\
\hline 9 & $50 \mathrm{M}$ & L 3 & B & $\mathrm{C}$ & 8 & 8 & 2 & -8 & 7 & 0 & - \\
\hline 10 & $36 \mathrm{~F}$ & L 2 & $\mathrm{C}$ & $\mathrm{E}$ & 8 & 8 & 12 & 2 & 7 & 2 & - \\
\hline 11 & $31 \mathrm{~F}$ & L 1 & $\mathrm{C}$ & $\mathrm{D}$ & 9 & 8 & 18 & 4 & 8 & 0 & - \\
\hline 12 & $27 \mathrm{M}$ & L 3 & $\mathrm{C}$ & $\mathrm{E}$ & 7 & 7 & -6 & -8 & 6 & 1 & - \\
\hline 13 & $34 \mathrm{M}$ & L 1 & B & $\mathrm{C}$ & 8 & 7 & 15 & 2 & 7 & 0 & - \\
\hline 14 & $46 \mathrm{M}$ & L 2 & $\mathrm{C}$ & $\mathrm{E}$ & 7 & 8 & 7 & -5 & 7 & 0 & - \\
\hline 15 & $25 \mathrm{~F}$ & L 3 & $\mathrm{C}$ & $\mathrm{E}$ & 9 & 6 & 14 & -2 & 8 & 2 & Wound infection \\
\hline 16 & $36 \mathrm{M}$ & L1 & $\mathrm{D}$ & $\mathrm{E}$ & 8 & 8 & 6 & 0 & 6 & 1 & - \\
\hline
\end{tabular}




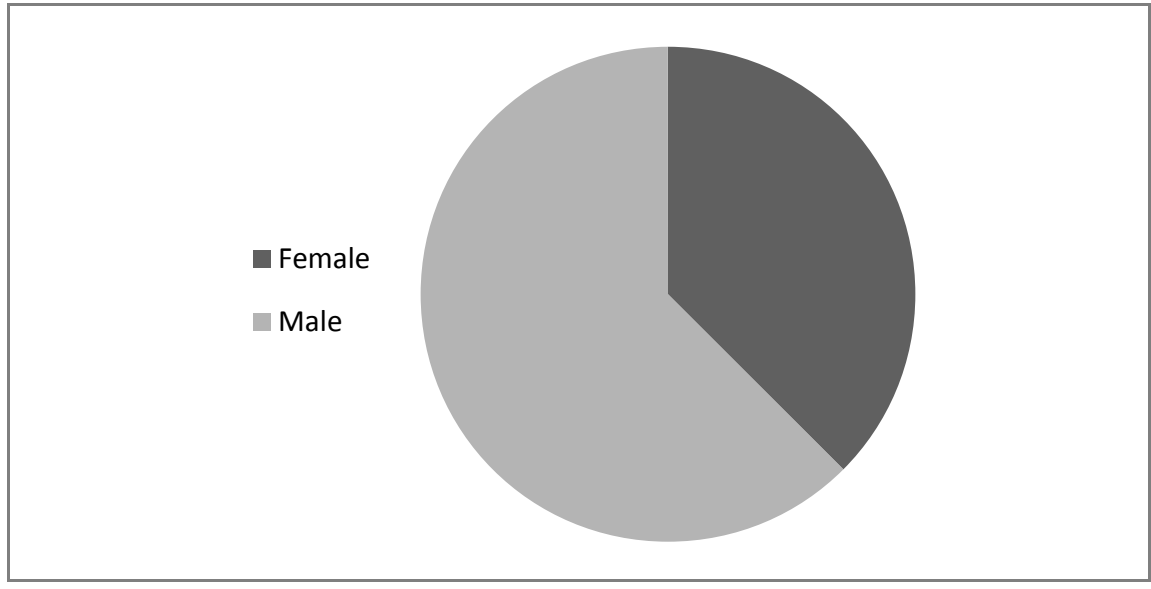

Figure 2. Sex distribution of all patients.

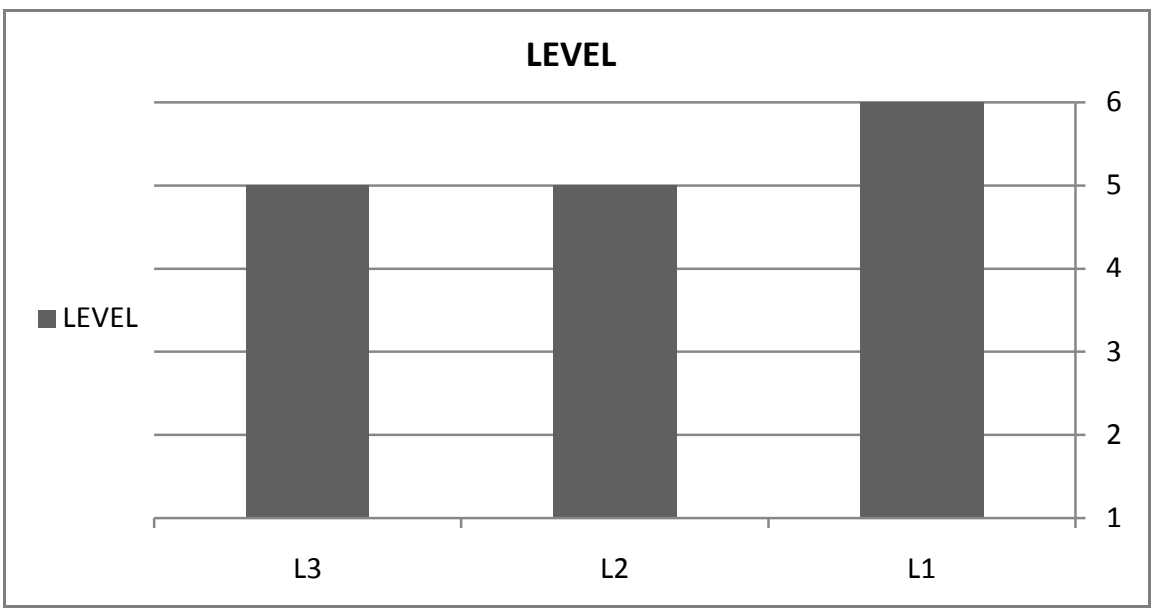

Figure 3. The levels of burst fracture in all patients.

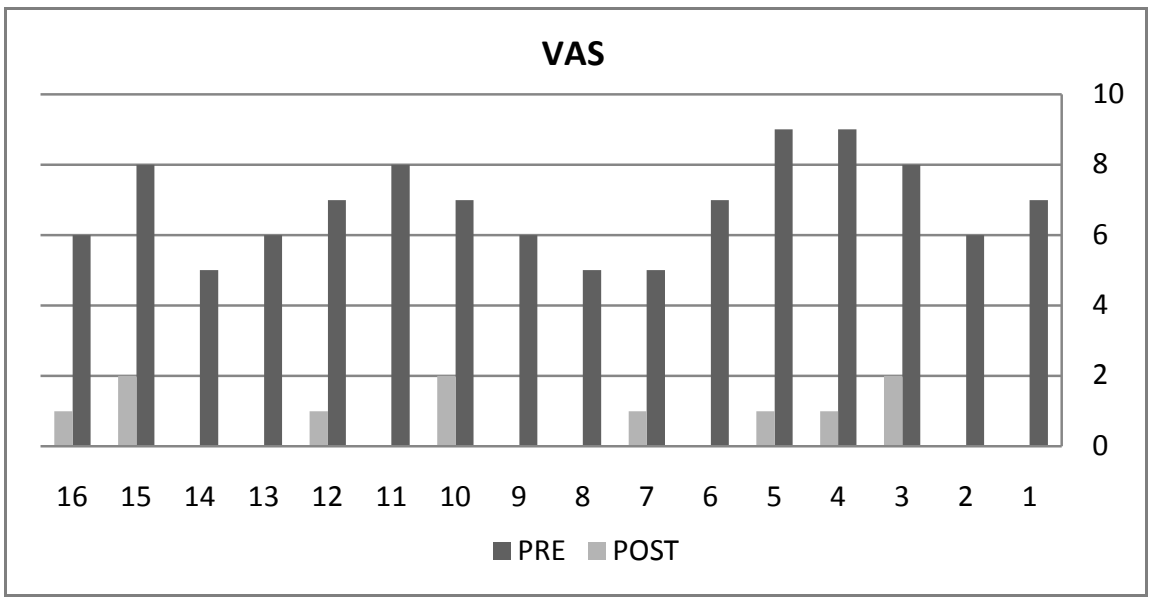

Figure 4. The difference between pre and post operative VAS.

\section{Summary of Complications}

Four cases had complication, 2 cases had intra operative complications during the surgery presenting $12.5 \%$ of all cases. The first complication (Case 5) had pe- 
ritoneal injury and managed directly by suturing the peritoneum with non absorbable sutures. The second (Case 1) had pleural injury and managed by suturing and inserting intercostal chest tube. The other 2 cases had postoperative complications presenting $12.5 \%$ of all cases, the first one (Case 15) had superficial wound treated by systemic antibiotics, the second (Case 8 ) had worsening of the kyphotic angle after failure of bone fusion. Supplementary posterior Instrumentation and fusion 2 levels above and 2 levels below the fracture level was done 6 months after the anterior approach.

\section{Case Presentation}

\subsection{Patient 2}

Male patient 25 years old involved in road traffic accident (RTA) had L2 burst fracture TLICS 8 and pre operative Frankel score C, kyphotic angel $5^{\circ}$ and VAS 6 , operation was done 5 days after hospital admission, mesh cage was used. The patient improved post operatively to Frankel score E, kyphotic angel to $1^{\circ}$ and VAS 0 , discharged from the hospital 7 days after surgery without complications (Figures 5-8).

\subsection{Patient 12}

Male patient 27 years old involved in RTA with L3 burst fracture with fracture lamina (three columns fracture) TLICS 7 and pre operative Frankel score C,kyphotic angel $-6^{\circ}$ and VAS 7 at first operated upon by anterolateral approach with usage of expandable cage, 5 days later we operated him with posterior approach to augment the instrumentation he was improved post operatively to Frankel score E, kyphotic angel to $-8^{\circ}$ and VAS 1 discharged from the hospital 10 days after surgery without complications (Figure 9, Figure 10).

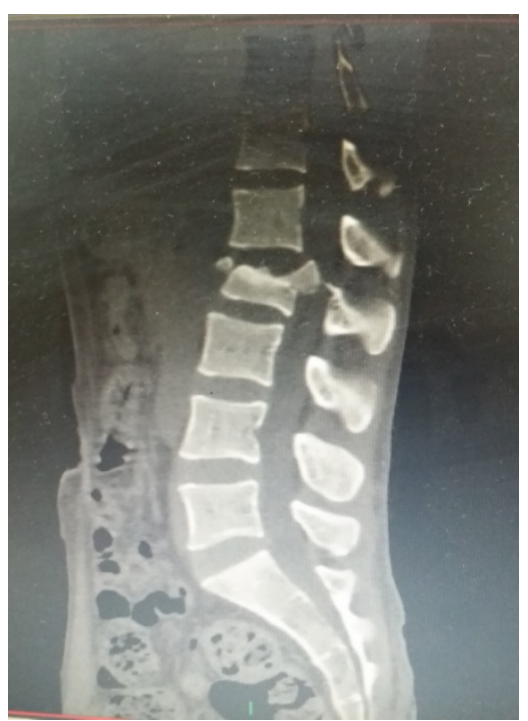

(a)

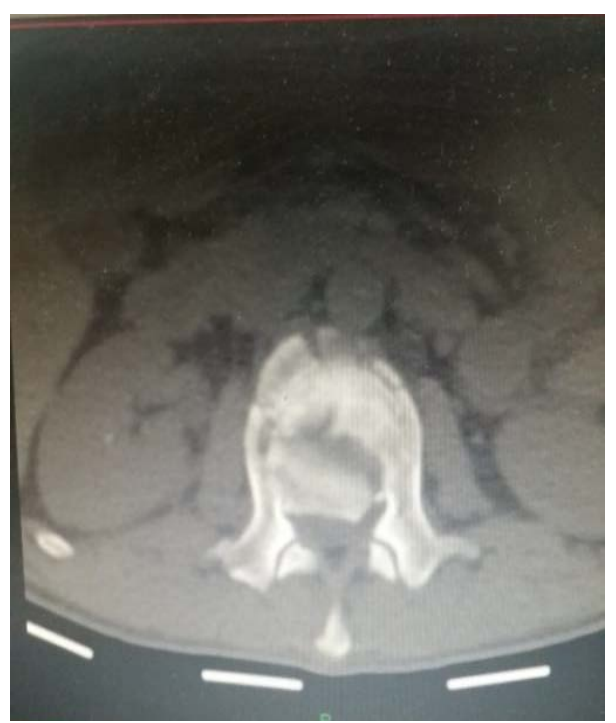

(b)

Figure 5. Pre operative CT spine sagital (a) and axial (b) views. 


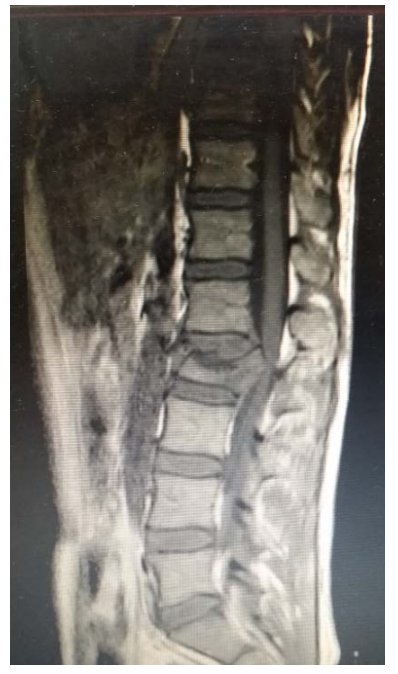

(a)

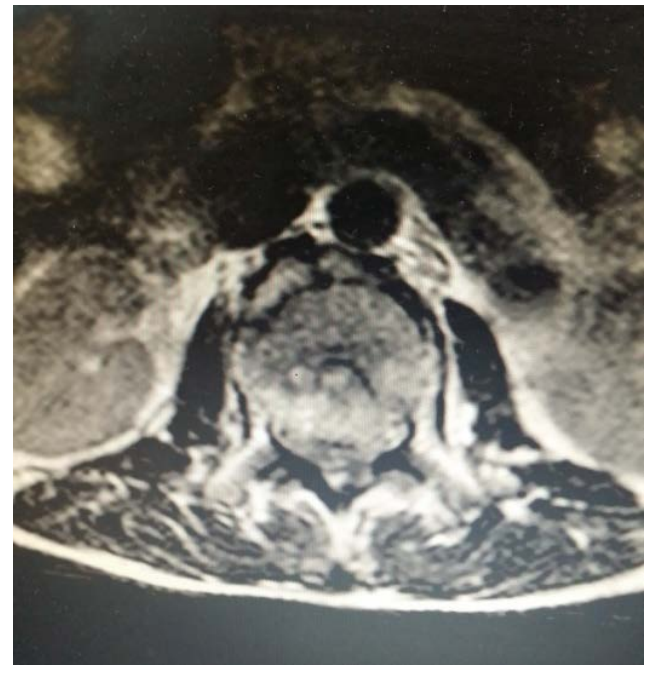

(b)

Figure 6. Pre operative MRI spine sagital (a) and axial (b) views.

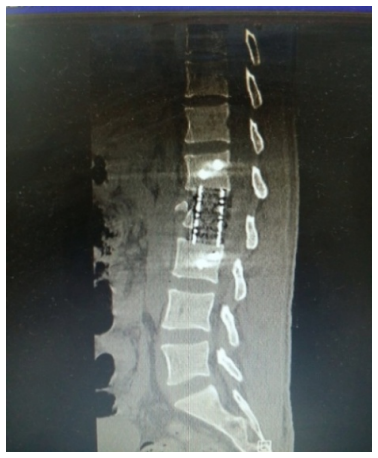

(a)

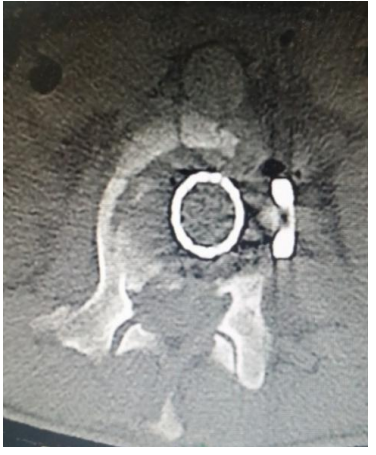

(b)

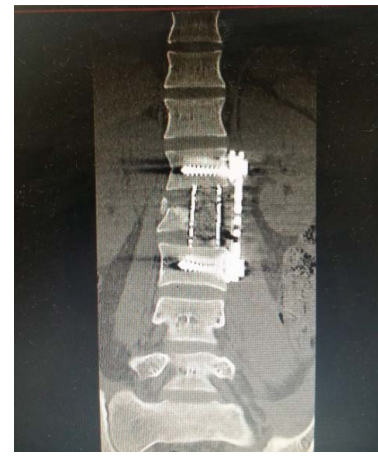

(c)

Figure 7. Post operative CT spine sagital (a), axial (b) and coronal (c) views.

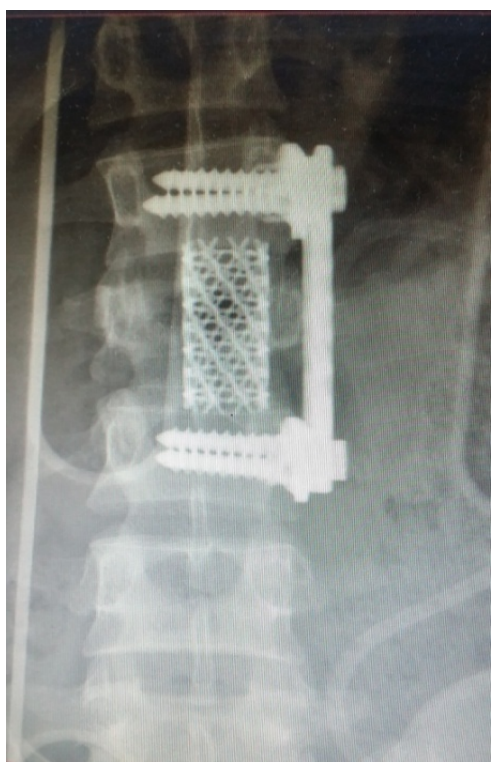

(a)

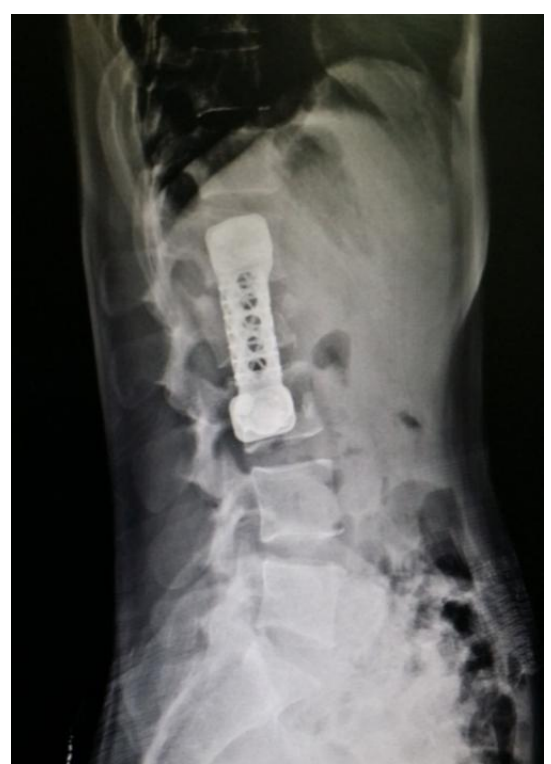

(b)

Figure 8. Post operative X ray AP (a) and Lateral (b) views. 


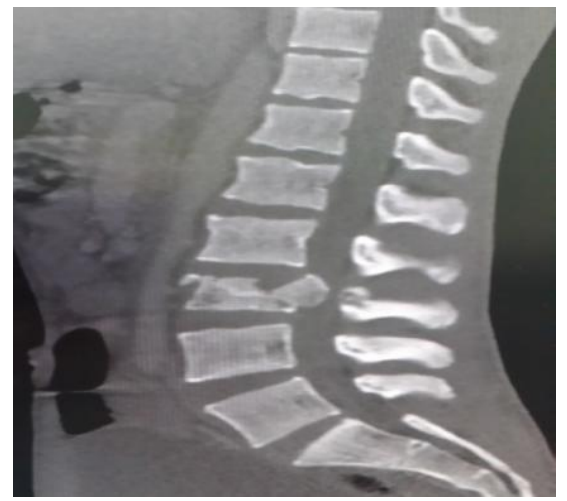

(a)

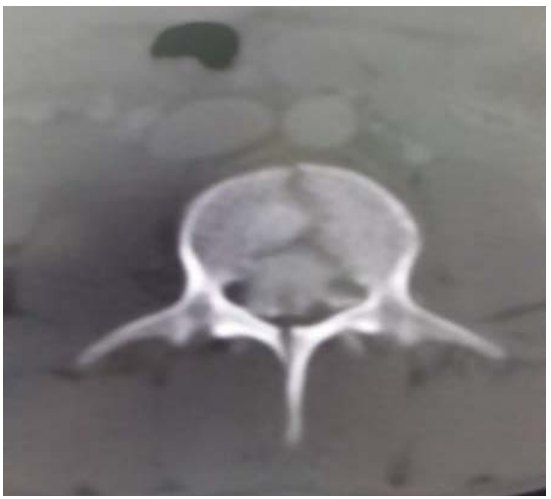

(b)

Figure 9. Pre operative CT spine sagital (a) and axial (b) views.

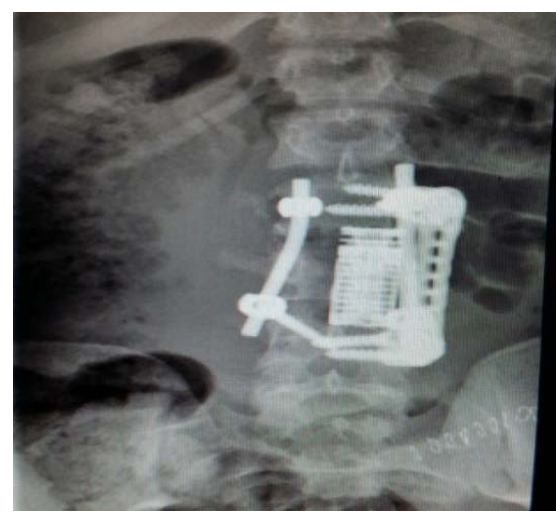

(a)

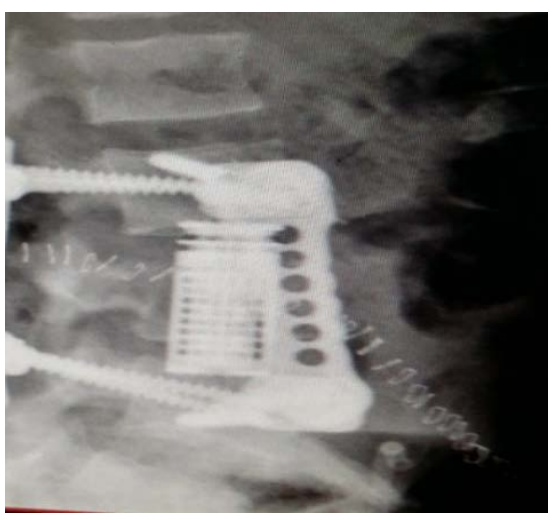

(b)

Figure 10. Post operative X ray AP (a) and Lateral (b) views.

\subsection{Patient 15}

A female patient 25 years old fell from height with L3 burst fracture. TLICS 6 and pre operative Frankel score C, kyphotic angel $14^{\circ}$ and VAS 8. she was operated upon anteriorly with usage of mesh cage. she improved post operatively to Frankel score E, kyphotic angel to $-2^{\circ}$ and VAS 2 she has superficial wound infection treated by systemic antibiotics and discharged from the hospital 15 days after surgery (Figure 11, Figure 12).

\section{Discussion}

The anterior approach allows removal of retro pulsed bone from the canal under direct vision as well as reconstruction of the anterior column with a strut graft. This approach protects the integrity of the posterior column and is associated with a sustained correction of angular deformity [16] [17] [18]. Regarding the neurological status of the patients which is assessed by Frankel score [6]. All of the patients improved at least one level after surgery except 2 cases of score A didn't improve. The kyphotic angle improved from the mean angle $8.8^{\circ}$ (range from -6 to $20^{\circ}$ ) before surgery to the mean angle $-1^{\circ}$ (range from $-10^{\circ}$ to $4^{\circ}$ ) after surgery and final follow up. A significant difference was seen between kyphotic 


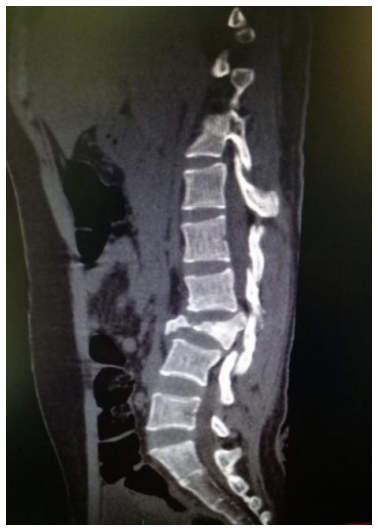

(a)

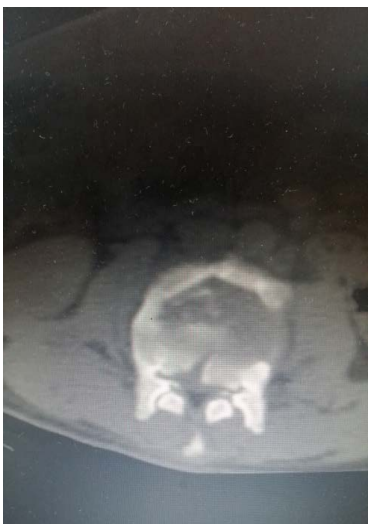

(b)

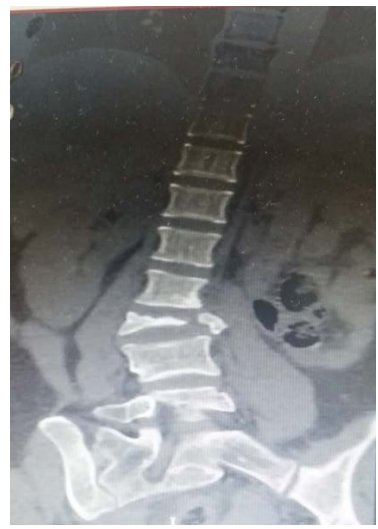

(c)

Figure 11. Pre operative CT spine sagital (a), axial (b) and coronal (c) views.

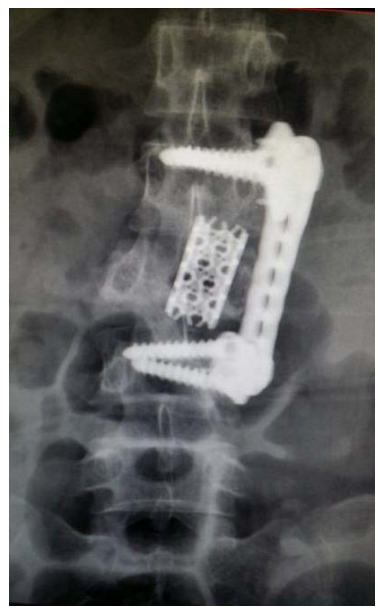

(a)

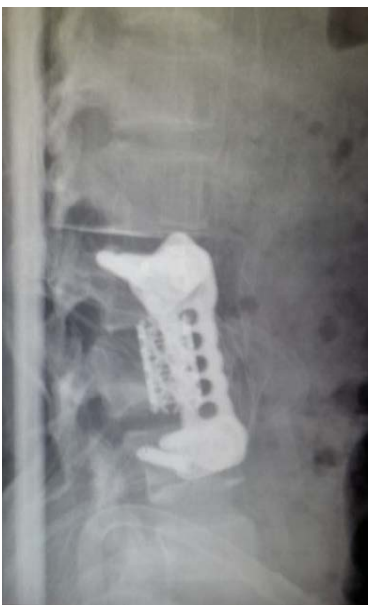

(b)

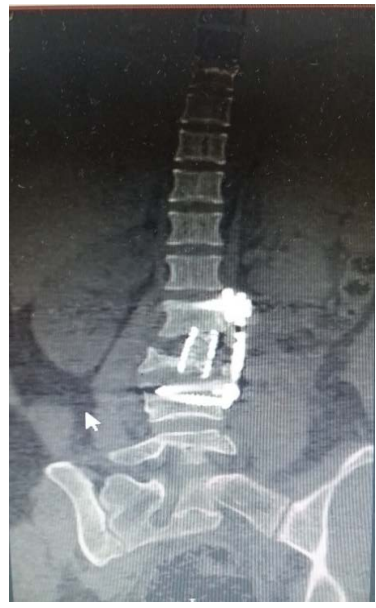

(c)

Figure 12. Post operative Follow up X ray AP (a), lateral (b) and coronal CT spine (c).

angle preoperatively and at final follow up $(\mathrm{p}=0.0001)$ in all cases. The total kyphotic correction was $9.9^{\circ}$ on average (range from -8 to 16). One patient (6\%) of our 16 patients treated with the anterolateral approach needed supplementary posterior Instrumentation and fusion 6 months after the anterior approach due to failure of bone fusion.

McAfee reported on complications associated with the anterior approach when used in patients with thoracolumbar fractures undergoing decompression and stabilization with various implants. The failure rate was $6 \%$ (two of $35 \mathrm{im}$ plants). The anterior approach in patients with VB fractures requires fixation of only one level rostral and caudal to the fractured VB, whereas in the posterior approach instrumentation may span five or more levels where the anterior column has been disrupted with secondary deformity. To optimize fusion, bone grafts are better maintained under compression [19] [20].

In cases of severely unstable lumbar burst fractures, anterior column reconstruction and decompression are necessary. To reconstruct the anterior column in lumbar spine, resection of the affected vertebra and strut bone graft or re- 
placement with a cage can be managed from an anterior approach. However, anterior instrumentation for L5 or S1 are restricted by anatomical factors such as the presence of major vessels, the iliopsoas muscles, and iliac crests, so the anterior approach is contraindicated in cases of L4, 5 fractures [5] [16] [21].

Anterior approach has some anatomical limitations due to the presence of major vessels so it needs surgeon familiar with this approach. Regarding our results and those of others we found that selection of Patients for anterior approach should be based on clinical and radiological criteria such as neurological deficit, kyphotic angle and anterior spinal canal compression for that Anterior approach is absolutely indicated in unstable burst fractures of L1, 2, 3 with incomplete neurologic deficits, load sharing scores (LSS) $\geq 7$, anterior canal compression with evidence of posterior longitudinal ligament or annular disruption and Relatively indicated in unstable lumbar burst fractures in neurologically intact patients or patients with Frankel score A and Anterior approach with supplemental posterior instrumentation is indicted in unstable burst fracture with sever kyphosis or severe three column injury.

\section{Conclusion}

Anterolateral approach is a feasible, effective, and safe approach for unstable lumbar burst fractures causing angular deformity with incomplete neurological deficit. Corpectomy with anterior approach and grafting is an effective treatment modality. Anterior approach not only provides successful correction of angular deformity by reconstruction of anterior and middle columns with fusion, but also it helps to improve the neurological status in patients with neurological deficits by safe and efficient decompression of the spinal canal. All of these are approved by our results.

\section{References}

[1] Vaccaro, A.R., Lim, M.R., Hurlbert, R.J., et al. (2006) Surgical Decision Making for Unstable Thoracolumbar Spine Injuries: Results of a Consensus Panel Review by the Spine Trauma Study Group. Journal of Spinal Disorders \& Techniques, 19, 1-10. https://doi.org/10.1097/01.bsd.0000180080.59559.45

[2] Langrana, N.A., Harten, R.D., Lin, D.C., Reiter, M.F. and Lee, C.K. (2002) Acute Thoracolumbar Burst Fractures: A New View of Loading Mechanisms. Spine, 27, 498-508. https://doi.org/10.1097/00007632-200203010-00010

[3] Thongtrangan, I., Le, H.N., Park, J. and Kim, D.H. (2006) Thoracic and Thoracolumar Fractures. In: Kim, D.H., Henn, J.S., Vaccaro, A.R. and Dickman, C.A., Eds., Surgical Anatomy \& Techniques to the Spine, 9th Edition, Sunders Elsevier, Philadelphia, 352-363.

[4] Lu, D.C., Lau, D., Lee, J.G. and Chou, D. (2010) The Transpedicular Approach Compared with the Anterior Approach: An Analysis of 80 Thoracolumbar Corpectomies: Clinical Article. Journal of Neurosurgery: Spine, 12, 583-591. https://doi.org/10.3171/2010.1.SPINE09292

[5] McCormack, T., Karaikovic, E. and Gaines, R.W. (1994) The Load Sharing Classification of Spine Fractures. Spine, 19, 1741-1744.

https://doi.org/10.1097/00007632-199408000-00014 
[6] Sasso, R.C., Best, N.M., Reilly, T.M. and McGuire, R.A.Jr. (2005) Anterior-Only Stabilization of Three-Column Thoracolumbar Injuries. Journal of Spinal Disorders \& Techniques, 18, S7-14. https://doi.org/10.1097/01.bsd.0000137157.82806.68

[7] McLain, R.F. (2004) Functional Outcomes after Surgery for Spinal Fractures: Return to Work and Activity. Spine, 29, 470-477. https://doi.org/10.1097/01.BRS.0000092373.57039.FC

[8] Danisa, O.A., Shaffrey, C.I., Jane, J.A., Whitehill, R., Wang, G.W., Szabo, T.A., et al. (1995) Surgical Approaches for the Correction of Unstable Thoracolumbar Burst Fractures: A Retrospective Analysis of Treatment Outcomes. Journal of Neurosurgery, 83, 977-983. https://doi.org/10.3171/jns.1995.83.6.0977

[9] Crutcher, J.P.Jr., Anderson, P.A., King, H.A. and Montesano, P.X. (1991) Indirect Spinal Canal Decompression in Patients with Thoracolumbar Burst Fractures Treated by Posterior Distraction Rods. Journal of Spinal Disorders, 4, 39-48.

[10] Korovessis, P., Baikousis, A., Zacharatos, S., Petsinis, G., Koureas, G. and Iliopoulos, P. (2006) Combined Anterior plus Posterior Stabilization versus Posterior Short-Segment Instrumentation and Fusion for Mid-Lumbar (L2-L4) Burst Fractures. Spine, 31, 859-868. https://doi.org/10.1097/01.brs.0000209251.65417.16

[11] Payer, M. (2006) Unstable Burst Fractures of the Thoracolumbar Junction: Treatment by Posterior Bisegmental Correction/Fixation and Staged Anterior Corpectomy and Titanium Cage Implantation. Acta Neurochirurgica (Wien), 148, 299-306. https://doi.org/10.1007/s00701-005-0681-5

[12] Miyakoshi, N., Shimada, Y., Abe, E. and Suzuki, T. (2010) Effects and Complication Measures of the Instrumentation Surgery for Spinal Deformity in the Elderly. Orthopaedic Surgery and Traumatology, 53, 1043-1051.

[13] Baron, E.M. and Albert, T.J. (2006) Medical Complications of Surgical Treatment of Adult Spinal Deformity and How to Avoid Them. Spine, 31, S106-S118. https://doi.org/10.1097/01.brs.0000232713.69342.df

[14] Hitchon, P.W., Tomer, J., Eichholz, K.M. and Beeler, S.M. (2006) Comparison of Anterolateral and Posterior Approaches in the Management of Thoracolumbar Burst Fractures. Journal of Neurosurgery: Spine, 5, 117-125. https://doi.org/10.3171/spi.2006.5.2.117

[15] Verlaan, J.J., Diekerhof, C.H., Buskens, E., van der Tweel, I., Verbout, A.J., Dhert, W.J., et al. (2004) Surgical Treatment of Traumatic Fractures of the Thoracic and Lumbar Spine: A Systematic Review of the Literature on Techniques, Complications, and Outcome. Spine, 29, 803-814. https://doi.org/10.1097/01.BRS.0000116990.31984.A9

[16] Kaneda, K., Taneichi, H., Abumi, K., Hashimoto, T., Satoh, S. and Fujiya, M. (1997) Anterior Decompression and Stabilization with the Kaneda Device for Thoracolumbar Burst Fractures Associated with Neurological Deficits. The Journal of Bone and Joint Surgery, American Volume, 79, 69-83.

https://doi.org/10.2106/00004623-199701000-00008

[17] McLain, R.F., Burkus, J.K. and Benson, D.R. (2001) Segmental Instrumentation for Thoracic and Thoracolumbar Fractures: Prospective Analysis of Construct Survival and 5 Year Follow-Up. The Spine Journal, 1, 310-323.

https://doi.org/10.1016/S1529-9430(01)00101-2

[18] Ghanayem, A.J. and Zdeblick, T.A. (1997) Anterior Instrumentation in the Management of Thoracolumbar Burst Fractures. Clinical Orthopaedics, 335, 89-100.

[19] McAfee, P.C. (1994) Complications of Anterior Approaches to the Thoracolumbar Spine. Emphasis on Kaneda Instrumentation. Clinical Orthopaedics and Related 
Research, 306, 110-111.

[20] McAfee, P.C., Bohlman, H.H. and Yuan, H.A. (1985) Anterior Decompression of Traumatic Thoracolumbar Fractures with Incomplete Neurological Deficit using a Retroperitoneal Approach. The Journal of Bone and Joint Surgery. American Volume, 67, 89-104. https://doi.org/10.2106/00004623-198567010-00012

[21] Suzuki, T. and Abe, E. (2009) Spinal Instrumentation for Thoraco-Lumbar Injuries: Causes and Prevention of Their Revision Surgery. Spine, 22, 851-858. 